In the series of 2,500 aspirations without complication reported by Stamey et al. (1965), one-third had a bacterial count of less than 100,000 organisms per $\mathrm{ml}$. The same workers showed that hydration reduced the bacterial counts to the 10,000-100,000 organisms per ml. range, but not lower, and that in $5-6 \%$ of infected urines a mixed growth was obtained.

The problem of satisfactory urine collection is a major one both inside and outside the hospital. The technique described here reduces the extra work necessary in carrying out multiple quantitative cultures, especially in paediatric, post-pantum, post-surgical, paraplegic, and elderly patients. Bladder puncture is a most convenient technique for use in the consultingroom, for, as we have shown, the specimen could be left lying about at room temperature and delivered to the laboratory for culture when convenient. In addition such specimens can be sent to the laboratory by post when packaged appropriately.
We should like to thank the Canterbury Medical Research Foundation for financial assistance.

Requests for reprints should be addressed to Dr. P. J. Little.

\section{REFERENCES}

Beard, R. W., McCoy, D. R., Newton, J. R., and Clayton, S. G. (1965) Lancet, 2,610 .

Brumfitt, W., Davies, B. I., and Rosser, E. ap I. (1961). Lancet, 2, 1059. Guze, L. B., and Beeson, P. B. (1956). New Engl. F. Med., 255, 474.

Kass, E. H. (1956). Trans. Ass. Amer. Phycns, 69, 56.

McFadyen, I. R., and Eykyn, S. J. (1968). Lancet, 1, 1112

Nelson, J. D., and Peters, P. C. (1965). Pediatrics, 36, 132.

Newman, C. G. H., O'Neill, P., and Parker, A. (1967). Brit. med. f., 2, 277.

Pryles, C. V. (1965). Pediatrics, 36, 128.

Stamey, T. A., Govan, D. E., and Palmer, J. M. (1965). Medicine (Baltimore), 44, 1.

\title{
Epilepsy and Oral Contraception
}

\author{
MICHAEL ESPIR,* M.A., M.B., M.R.C.P. ; M. E. WALKER, † M.A., M.B., M.R.C.P. ; \\ JUNE P. LAWSON, $\ddagger$ M.B., CH.B., D.OBST.R.C.o.G.
}

Brit. med. F., 1969, 1, 294-295

Cummary : A controlled cross-over trial in 20 epileptic $\checkmark$ women, receiving regular anticonvulsant therapy showed that an oral contraceptive with a low oestrogen/ progestogen content had no significant effect on the average frequency of fits compared with identical dummy tablets.

\section{Introduction}

The particular relevance of oral contraception to patients with epilepsy is readily apparent, yet little information is available about the effects of the different contraceptive pills in such cases (Brit. med. F., 1967). There are theoretical grounds for suspecting that oral contraceptive drugs might influence the control of fits, and Mears (1965) and the World Health Organization (1966) recommend careful evaluation of patients with epilepsy before oral contraception is started. Isolated case reports have produced conflicting evidence and no controlled study is available. The purpose of this paper is to report the effect of a particular contraceptive pill (Norinyl-1\$) on a group of epileptic women.

\section{Material and Methods}

Twenty-three women with epilepsy and having menstrual periods were chosen. All had been investigated in the departments of neurology and electroencephalography in Leicester between 1960 and 1967. We included only those who had been on an anticonvulsant regimen which had been unchanged for several months or years and which appeared to be the most suitable that could be offered in each case. Patients already receiving oral contraception or regular treatment with drugs other than anticonvulsants were excluded, and care was taken to ensure that none had a past history of cardiac, renal, or

- Consultant Neurologist, Leicester Royal Infirmary.

t Neurological Registrar, Leicester Royal Infirmary.

\# Clinical Advisor, Syntex Pharmaceuticals Ltd.

S Norinyl-1 contains $0.05 \mathrm{mg}$. of mestranol and $1 \mathrm{mg}$. of norethisterone. thrombotic disease. Once a patient was regarded as suitable for the trial she was told that we were attempting to evaluate the effect of a drug which, though it had been used in other conditions, had not previously been used specifically for epilepsy. She was told that it was a hormone preparation, which had an effect on menstruation and fertility. Alternate patients were given Norinyl-1 and told to take one tablet each evening for 21 consecutive days out of 28 , and at the end of three such monthly cycles a dummy tablet, identical in appearance, was substituted unbeknown to the patient, who followed the same regimen for another three months. The other patients took the dummy tablet and Norinyl-1 in the reverse order. All patients continued to take their established anticonvulsant therapy. All patients were provided with a special card containing three squares for each day of the trial on which they recorded the taking of tablets, menstrual loss, and the number and type of any epileptic attacks. They were seen and their cards checked at monthly intervals.

\section{Results}

Three patients defaulted at an early stage, leaving 20 who completed the trial. Their main clinical and electroencephalographic (E.E.G.) features are shown in the Table, with the frequency of fits before and during the trial in each case. This shows that two patients were free of fits during the trial period. In two instances there were notable discrepancies between the number of fits during the trial and the average incidence previously. One patient (Case 19) receiving Norinyl-1 had 38 attacks during a one-week period when she was suffering from gastroenteritis. An increase in fit frequency also occurred in a patient (Case 7) taking the dummy preparation, when she developed a boil on her face with pronounced cellulitis. Overall there was a remarkable constancy in the total number of fits during and before the two periods of the trial. The first seven patients (Cases 1-7) had fewer fits while taking Norinyl-1, and the last 11 (Cases 10-20) had fewer fits on the dummy. By $\chi^{2}$ analysis this difference is not greater than might be 
expected by chance. Correlations were sought and not found between fit frequencies and the type of epilepsy, the E.E.G. findings, and the sequence in which the trial drugs were administered. Norinyl-1 was not more effective than the dummy in those patients whose fits had been related to menstruation.

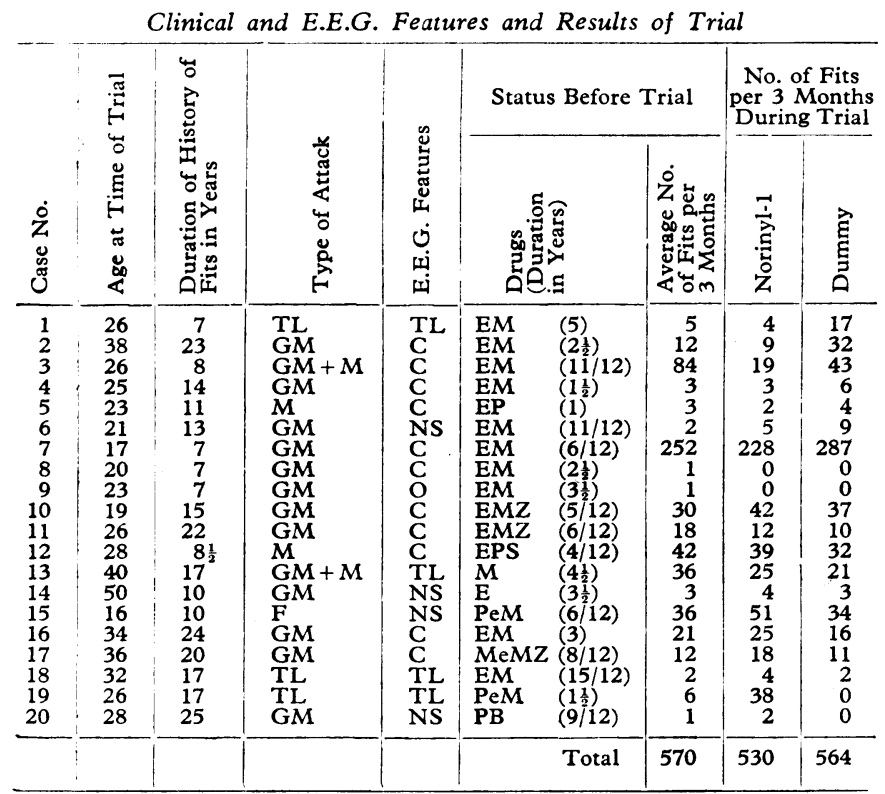

$\mathbf{P}=$ Phenobarbitone. $\quad \mathbf{E}=$ Phenytoin (Epanutin). $\quad \mathrm{Pe}=$ Ethotoin (Peganone).

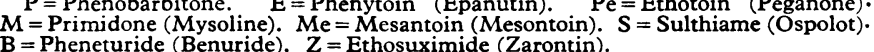

$\mathrm{B}=$ Pheneturide (Benuride). $Z=$ Ethosuximide (Zarontin). other than temporal lobe

E.E.G. Features: $\mathrm{C}=$ Centrencephalic. $\mathrm{TL}=$ Temporal lobe. $\mathrm{NS}=$ Non-specific abnormalities. $\mathrm{O}=$ Normal.

No patients experienced troublesome side-effects during the trial, except one who developed symptoms of anticonvulsant toxicity shortly after starting Norinyl-1.

Case 17. - This patient had been free from fits on a regimen of primidone $500 \mathrm{mg}$. t.d.s. ethosuxide $250 \mathrm{mg}$. t.d.s. and mesantoin $100 \mathrm{mg}$. t.d.s. for eight months before the trial. A few weeks after starting Norinyl-1 she developed marked drowsiness, dysarthria, and ataxia. The Norinyl-1 was therefore stopped, the primidone was reduced to $250 \mathrm{mg}$. t.d.s., and the toxic symptoms subsided. Unfortunately her fits recurred. Later she entered the trial afresh and had 18 fits while on Norinyl-1 and 11 while on the dummy. After the trial her primidone was gradually increased again, her fits lessened, and the symptoms of toxicity did not recur.

Despite questioning all the patients about side-effects from their anticonvulsant drugs, no similar examples were encountered.

\section{Discussion}

Norinyl-1 was selected for this trial because it was thought that the low oestrogen content would be unlikely to cause fluid retention and thus aggravate fits. Funthermore, it was hoped that with this type of preparation the risks of serious side-effects would be minimized, recent evidence suggesting that high dosage of oestrogen and the sequential types of oral contraceptives may be more dangerous (Brit. med. F., 1968).

The effects of oestrogenic and progestogenic agents on metabolism in general and on cerebral metabolism and epilepsy in particular are largely unknown, but there are several theoretical mechanisms whereby oral contraceptives might affect the control of epilepsy. The fact that fits tend to be more frequent just before and during menstruation, and less frequent during the mid-luteal phase, suggests that there may be some link between female hormones and epilepsy (Laidlaw, 1956). Progestogenic activity is maximal in the mid-luteal phase, declining sharply before menstruation, and Costa and Bonnycastle (1952) advanced experimental evidence for an anticonvulsant effect of progestogens. However, in our patients comparison of the average frequency of fits during the first three weeks of each of the three cycles on Norinyl-1 with the last week of the cycles when it was not taken showed no difference, and thus no anticonvulsant effect could be attributed to the small amount of progestogen in Norinyl-1.

Though Ansell and Clarke (1956) concluded that disturbances of water storage were not primarily responsible for catamenial epilepsy, it is well known that fits may be aggravated by overhydration, and it has long been suspected that premenstrual fluid retention may be relevant. The oestrogen/ progestogen balance is probably important in this respect, and may be modified by oral contraceptives.

It is also possible that the oral contraceptive may influence the protein-binding or hepatic detoxication of anticonvulsant drugs, perhaps by competing for binding sites, and this may have accounted for the symptoms of anticonvulsant toxicity as described in our patient.

In the face of these theoretical considerations the paucity of clinical evidence is surprising. Copeman (1963) reported the case of a young woman who was free of epileptic attacks during two years of oral contraception with an unspecified synthetic oestrogen/progestogen combination, and subsequently relapsed when the latter was discontinued. McArthur (1967) reported a patient whose fits were more frequent while taking a predominantly oestrogenic pill than while taking a predominantly progestogenic one. Toivakka (1967), in a study from Finland, found that a predominantly oestrogenic pill caused an aggravation of epilepsy in only 1 out of 11 epileptic women. This patient had reduced her anticonvulsant therapy just before the beginning of the trial.

Epilepsy may also be influenced by psychological factors, such as the peace of mind resulting from the use of an effective method of contraception; but such an effect was excluded by the design of this trial. Sometimes adding a new drug, even with no anticonvulsant action, seems to help, but this was not evident in our cases.

In conclusion we would emphasize that, although the oral contraceptive used in this trial did not significantly alter the frequency of fits, the same cannot necessarily be assumed for other contraceptive drugs.

We should like to thank the medical director of Syntex Pharmaceuticals Ltd. for helpful criticism and for the supply of Norinyl-1 and dummy tablets. We are also grateful to Dr. J. J. Danik for reporting the E.E.G.s; to Mrs. K. Brooke for the statistical arialysis ; to Mr. E. J. Fitchett, chief pharmacist at the Leicester Royal Infirmary, for dispensing the tablets; and to Dr. P. Millac for valuable advice in the preparation of this paper.

Requests for reprints should be sent to Dr. Michael Espir, Department of Neurology, Derbyshire Royal Infirmary, Derby.

\section{REFERENCES}

Ansell, B., and Clarke, E. S. (1956). Lancet, 2, 1232.

Brit. med. f., 1967, 3, 162.

Brit. med. F., 1968, 2, 187

Copeman, H. (1963). Med. F. Aust., 2, 969.

Costa, P. J., and Bonnycastle, D. D. (1952). Arch. int. Pharmacodyn., 91,330 .

Laidlaw, J. (1956). Lancet, 2, 1235.

McArthur, J. (1967). Brit. med. F., 3, 162.

Mears, E. (1965). Handbook on Oral Contraception, p. 69. London.

Toivakka, E. (1967). Arzneimittel-Forsch., 17, 1085.

World Health Organization (1966). Wld Hlth Org. techn. Rep. Ser., No. 326, p. 19. 